\title{
A la revolución por la secularización. Rupturas y continuidades en los discursos republicanos del Sexenio Democrático
}

À la révolution par la sécularisation. Ruptures et continuités dans les discours républicains du "Sexennat Démocratique "

To the revolution for secularization. Ruptures and continuities in the republican discourses of the Democratic Sexenio

\section{Alicia Mira Abad}

\section{OpenEdition}

\section{Journals}

Edición electrónica

URL: http://journals.openedition.org/bhce/1971

DOI: $10.4000 /$ bhce.1971

ISSN: 1968-3723

Editor

Presses Universitaires de Provence

Referencia electrónica

Alicia Mira Abad, «A la revolución por la secularización. Rupturas y continuidades en los discursos republicanos del Sexenio Democrático », Bulletin d'Histoire Contemporaine de l'Espagne [En línea], 55 2020, Publicado el 01 septiembre 2020, consultado el 02 diciembre 2020. URL : http:// journals.openedition.org/bhce/1971 ; DOI : https://doi.org/10.4000/bhce.1971

Este documento fue generado automáticamente el 2 diciembre 2020

Bulletin d'histoire contemporaine de l'Espagne 


\section{A la revolución por la secularización. Rupturas y continuidades en los discursos republicanos del Sexenio Democrático}

À la révolution par la sécularisation. Ruptures et continuités dans les discours républicains du "Sexennat Démocratique » To the revolution for secularization. Ruptures and continuities in the republican discourses of the Democratic Sexenio

\section{Alicia Mira Abad}

\section{Introducción}

1 La aproximación a los discursos de los revolucionarios septembrinos resulta compleja, especialmente cuando inciden en la cuestión religiosa. Sin embargo, es una pieza clave para analizar cómo se construye en España el imaginario de modernidad ligado a la revolución. Un análisis centrado en la secularización, no permite discernir claramente las « disposiciones estructurales, principalmente jurídicas, que ha establecido el Estado, ni las relaciones de fuerza entre los grupos sociales que forman parte activa de estas decisiones ». Pero el Sexenio democrático no nos deja otra opción puesto que no existe un horizonte claro de laicidad que permita modificar sustancialmente el «funcionamiento de las instituciones, tanto religiosas como políticas ${ }^{1}$. Nuestros republicanos y demócratas se mueven entre interminables párrafos engarzados en una trama historicista, artificios retóricos y simbólicos en una trama historicista que gira en torno a la dinámica política y el devenir nacional. Su objetivo era construir una narrativa revolucionaria en la que es muy difícil discernir entre los golpes de efecto 
destinados a despertar la emotividad, las estrategias de persuasión ideológica y sus propias convicciones en torno al alcance secularizador. La acción política que se propugna es en muchas ocasiones retórica pero no exenta de interés, puesto que evidencia el esfuerzo legitimador de un proceso revolucionario que aspiraba al cambio sin derivar hacia posiciones radicales.

2 El criterio seguido en la selección de textos se centra en tratar de verificar las diversas vías desarrolladas por sus autores para encontrar los hilos conductores o las continuidades históricas de la propia revolución. En esta labor, el perfil ecléctico que conscientemente asumen muchos de ellos es fruto de la evolución de su pensamiento, en contacto con las corrientes filosóficas europeas del momento y de sus propias vivencias en unos años de gran densidad política. Algunos de ellos modificaron sustancialmente sus posiciones iniciales en torno a la idea de revolución y el alcance que debían tener las medidas secularizadoras. Para muchos republicanos los « agitados años del Sexenio " supusieron una auténtica liberación personal en la conciencia religiosa ${ }^{2}$, de manera que junto al ideal krausista de una humanidad armónica, convivieron los planteamientos de raíz hegeliana, positivista o neo-kantiana. Un eclecticismo que desde las posiciones más conservadoras y reaccionarias evidenciaba la endeblez del pensamiento progresista ya que «los krausistas poco convencidos" encontraban así la forma de "derivar al positivismo " ${ }^{3}$.

Desde los primeros momentos, tras la sublevación iniciada contra Isabel II, y a pesar de esa aparente dispersión ideológica, los republicanos y demócratas más relevantes intentaron construir un relato fundacional en torno a un ideal de República ajeno a la abstracción de los conceptos políticos y al radicalismo jacobino, aunque sin renunciar al recuerdo de la gran revolución. A esa narrativa se suman las referencias a un derecho natural latente que la ley del progreso se encargaba de activar, ligado en muchos de los textos a la propia evolución del cristianismo, lo cual constata la dificultad para aunar unos anhelos colectivos de cambio.

4 La Revolución francesa se presenta como primer punto de inflexión que abría el paso a la modernidad. El gran símbolo de ruptura con el antiguo régimen se convierte, después de casi un siglo, en experiencia que permite legitimar los horizontes de expectativa revolucionarios ${ }^{4}$. En ese proceso las diversas fases, sus actores, derivas políticas y virajes radicales se diluyen. La gran revolución emerge así como una referencia compacta, que puede ser insertada en una realidad tan distinta y distante en el tiempo como la española de 1868 . Se trata de una labor que requiere gran destreza selectiva a la hora de construir un relato coherente. Precisamente las alusiones a la secularización tienen por objetivo modular el discurso del cambio, ajustándolo al contexto sociopolítico español. El progreso se hace visible a través de la libertad de cultos, el matrimonio civil o la secularización de los cementerios como parte de un recorrido universal de avance hacia la modernidad, pero también nacional, rastreable en el pasado de un pueblo amante de la libertad. Es el gran reto de los republicanos : inscribir la ruptura democrática derivada de la revolución en una genealogía liberal que integrara tradición nacional e influencias simbólicas foráneas ${ }^{5}$.

5 Puede que en la búsqueda de las diversas líneas de continuidad que vertebran los discursos republicanos cause cierta confusión la eclosión anticlerical y en muchos casos anticatólica. Un análisis profundo muestra que no suele cuestionarse la religión e incluso se considera una parte esencial de la sociedad que los revolucionarios pretendían cambiar. Imbricada en la historia, forma parte esencial de un discurso 
identitario que enlaza la idea de un "cristianismo (que) lejos de estar lejos del progreso, es su causa $»^{6}$. Las alusiones al cristianismo juegan en este sentido un papel fundamental. Gerhart Lander apunta que desde sus orígenes los « grandes conceptos de la cristiandad» fueron "concebidos como cosas inmanentes a este mundo, como hechos en el tiempo " y al mismo tiempo, " como trascendentes, invisibles, triunfales y eternos en el otro mundo ». Es esta « una de las grandes paradojas del cristianismo » de manera que « un concepto como el de Iglesia puede aparecer bajo estos dos aspectos sin dejar de ser en último extremo un único concepto». Por su parte Reeves otorga mucha importancia a la construcción de un mesianismo « dentro de la historia, no después de ella $»^{7}$. Para Arendt estos elementos no prueban que la doctrina cristiana fuese revolucionaria en sí misma ya que «fue precisa la modernidad para liberar los gérmenes revolucionarios contenidos en la fe cristiana». Aunque el componente cristiano es fundamental para entender la vinculación de la secularización con el fenómeno de las revoluciones y la construcción de su legitimidad ${ }^{8}$.

6 La abundancia de referencias al cristianismo en los textos analizados lo suscriben. Constituyen la fórmula idónea para integrar conceptos aparentemente tan incompatibles como revolución, libertad, progreso o modernidad con la idea de un orden ligado al sentido común y el propio devenir histórico. En ellas la secularización, encabezada por la libertad de cultos, es entendida como proceso inherente a la propia revolución, aunque las interpretaciones sobre su materialización política y social adquirieron múltiples matices. Fue utilizada como estrategia política para transmitir la imagen de un cambio visible y contundente y como proceso ligado a la razón derivada del derecho natural y de la historia. Desde planteamientos secularizadores se cuestiona la superstición, la ignorancia, la posición del clero y de la Iglesia ante la modernización y su desviación respecto al camino marcado originariamente por el cristianismo. El aparato católico se presenta así como un quiebro en esa trayectoria inicial al convertirse en una fuente de poder imbricada en las instituciones y en el imaginario social a partes iguales, que la revolución tenía la ocasión de restaurar. El pathos revolucionario en torno a un tiempo nuevo convive con la idea de recuperar un pasado desviado por la corrupción e incluso apunta hacia un horizonte igualitario, como se observa en uno de los numerosos opúsculos publicados tras el estallido revolucionario : el « hombre-Dios » en sus « dogmas liberales » al « siervo y al tirano llamó : iguales » .

7 La revolución concebida como fuerza latente, o espíritu universal se despliega en suelo patrio a partir de referencias históricas propias. Al igual que en otros lugares podía identificarse una especie de linaje del liberalismo hispano, visible por primera vez en las Cortes de Cádiz, el « periodo más glorioso de nuestra historia » porque " nos dieron libertad y patria, sin necesidad de esas presidencias, semejantes a las monarquías $»^{10}$. En el citado opúsculo se menciona al " pueblo, los hijos de Pelayo, los héroes de Bailen, de Zaragoza, los mártires en fin del dos de Mayo » como depositarios de la semilla revolucionaria ${ }^{11}$. El eclecticismo anteriormente señalado y los virajes en el discurso sobre la predisposición del pueblo español para la revolución están estrechamente vinculados a la evolución política. El pueblo justo, depositario de la libertad desde tiempo inmemorial se convierte en " levantisco y turbulento », de " espíritu aventurero y belicoso » en los últimos años del Sexenio. Las insurrecciones cantonales han terminado con la república, un hecho que para el periodista catalán Güell y Mercader, situado en la órbita de Castelar, demuestra que el pueblo francés es el único que realmente "guarda en su genealogía su audacia reformista" mientras que los españoles son una «masa de población compuesta de gente novelera, inquieta, mal 
avenida con los hábitos de trabajo, dispuesta siempre para todo lo extraordinario " y con una notable « falta de sentido práctico $»^{12}$.

Desde los primeros momentos del estallido revolucionario identificamos un discurso sin fisuras, que desde una aparente compacidad se proyecta como un todo definido por sus objetivos de cambio. A lo largo de los seis años siguientes ese planteamiento inicial se enreda y los componentes que forman parte de ese primer imaginario se dispersan. El análisis de la secularización en los discursos nos ayuda a identificar la prevalencia de un impulso ideológico o meramente retórico. Tras unas medidas secularizadoras presentadas como baluarte de la modernidad subyace el interés por mantener vivo el espíritu revolucionario inicial. Tras la caída de Isabel II la unidad republicana se construye en torno a una " discontinuidad fuerte ", entre un mundo anterior, arcaico, condenado a desaparecer y la emergencia de una nueva realidad sociopolítica. Con la aprobación de la Constitución de 1869 y el establecimiento de un sistema monárquico, la cohesión de los republicanos pervive precisamente a través del rechazo a un texto constitucional que traiciona los ideales revolucionarios. Pronto emergen las divergencias sobre cuestiones como "el socialismo, el federalismo o la estrategia política más conveniente $\aleph^{13}$. A medida que el primer impulso revolucionario inicial pierde fuerza los republicanos se ven obligados a construir una coartada que legitime la revolución en constante diálogo con un pasado liberal. Aparecen entonces las "líneas de continuidad» con el derecho natural y la historia para "remontar el fraccionamiento de la sociedad como comunidad $»^{14}$. Se hace necesario sincronizar los acontecimientos en España con otras experiencias revolucionarias externas para aquilatar la revolución, alejando al mismo tiempo el fantasma de la ruptura como entrada de la anarquía. Manuel de la Revilla se refiere a ese primer momento en el que « la razón calla y la pasión se agita (...) ¡Periodo bello como la infancia, pero infecundo como ella; periodo heroico y verdaderamente épico, pero perturbador y peligroso; periodo de dramáticas peripecias, de sublimes episodios, pero también de sangriento y doloroso desenlace $»^{15}$.

\section{El modelo revolucionario y sus equivalencias}

En los discursos progresistas la construcción de un supuesto paradigma francés se proyecta como una especie de eterno revolucionario, un todo homogéneo e inmutable, perfecto para completar la exaltación revolucionaria nacional. Así la defensa de la ley del matrimonio civil se presenta como consecuencia lógica de la libertad religiosa y "de pensar ", derivada a su vez de la reforma protestante y de la Revolución francesa ${ }^{16}$. Porque en realidad las revoluciones no son «movimientos militares» o "simples motines", sino un "adelanto para la humanidad». La Revolución francesa fue la primera en «levantar el espíritu público » y por tanto puede considerarse « un paso dado hacia el progreso » en el siglo de « la electricidad y del vapor ${ }^{17}$.

El gran referente revolucionario se proyecta envuelto en un "estilo emocional» romántico, cuya " voluntaria indisciplina y heterogeneidad ${ }^{18}$ dificulta la comprensión del mensaje regenerador. La intuición, el sentimiento, la crítica al orden establecido y la historicidad son las fórmulas que expresan el progreso en España. Evidencian un pensamiento teórico débil del que son conscientes algunos republicanos como Manuel de la Revilla, que en 1876 refuta las acusaciones de Menéndez Pelayo de anticatólico y antipatriótico afirmando que no existe un pensamiento científico o filosófico español, 
aunque admitirlo sea "doloroso para nuestro orgullo nacional $»^{19}$. El ideal modernizador en España no se fundamenta en un desarrollo autóctono de manera que el Estado se proyecta como una especie de "creador de la modernidad", impulsor de un cambio paradójico que a falta de un horizonte real de progreso parte de lo « lo viejo » para hacer «lo nuevo $»^{20}$. Las referencias al desarrollo de otros países contribuyen a la construcción de una "ilusión histórica" racionalizada sobre la experiencia de otros ${ }^{21}$. La revolución asienta un ideal de progreso por " acumulación ", que se resiste a perder los anclajes culturales, frente a otro por "sustitución », en el que prevalecería el carácter autónomo, dinámico o creador ${ }^{22}$. Estos planteamientos nos ayudan a entender cómo en un mismo discurso puede convivir una interpretación de la revolución como discontinuidad necesaria pero también como proceso restaurador de una legitimidad pasada. Revilla señala en este sentido que « el ideal revolucionario está delante, no detrás de nosotros " $\mathrm{y}$ « conviene mirar lo presente y lo futuro y no buscar el símbolo político en edades que no volverán ». Pero al mismo tiempo reivindica la existencia de un hilo conductor, no tanto desde la historia, sino ligado al derecho natural que se materializa en una «soberanía moral " universal porque «no todo se debe a la voluntad caprichosa de los hombres, ni las vicisitudes de la historia, ni los vaivenes de la política " sino a «las leyes inmutables de la naturaleza ", grabadas en "nuestra conciencia y nuestra razón $»^{23}$. Castelar, en cambio, recurre a las referencias históricas para señalar que "la República federal viene a reanudar nuestra historia patria cortada » por « el oleaje de las irrupciones extranjeras $»^{24}$. Ruptura y continuidad se alternan en los discursos para legitimar una revolución que en cualquier caso no se presenta ajena a la tradición española. No « es preciso negar el pasado sino que basta justificarlo como una serie de momentos necesarios para llegar a la plenitud del presente $»^{25}$.

11 La construcción de un discurso coherente que aproxime el paradigma francés al contexto español constituye todo un reto para los republicanos. Antonio Moliner, señala en este sentido que el espectro de la Revolución francesa no solo se considera la puerta a la modernidad, también representa el «temor a que el pueblo tenga un verdadero protagonismo » porque en realidad «sus aspiraciones no coinciden con las de los grupos dirigentes $»^{26}$. Algunos republicanos como Revilla se refiere en un sentido negativo al « unitarismo a la francesa, centralizador, absorbente y autocrático » que reviste al «Estado de facultades monstruosas ${ }^{27}$. Sin embargo, en la mayor parte de los discursos analizados, la Revolución francesa se convierte en una especie de a priori, una constante metahistórica independiente de toda experiencia. Desde 1789, distinguimos en el propio concepto de revolución una "gradación de estratos temporalmente diferentes se mezclan y dosifican de distinto modo en función del posicionamiento político", adquiriendo una propiedades semánticas "extensibles, ambivalentes y ubicuas $»^{28}$ que permiten delimitar la naturaleza de los cambios a escala nacional ${ }^{29}$. Extraída la dinámica histórica del proceso revolucionario francés nuestros republicanos la refieren en sus escritos como justificación del cambio, del cumplimiento de la ley del progreso y como síntoma de modernidad, para dotar al proyecto republicano de unicidad, irreversibilidad y permanencia.

12 Uno de los ejemplos más claros de utilización del paradigma francés nos la ofrece Emilio Castelar en su prólogo a Thiers. La compara con una gran inundación cuya fuerza devastadora fue terrible para quienes "sufrieron su primer impulso", pero como toda una bendición para quienes « heredaron aquella edad creadora ». A pesar del desorden y la violencia, la revolución no podía ser sustituida por la reforma. Los 
obstáculos insuperables de la época, «la resistencia de las instituciones antiguas » y en concreto de la Iglesia, mezclada con el poder civil « en términos de ser su cortesana o su señora », solo podían ser superados por una revolución cuyos « excesos abominables » están justificados por dichas resistencias. Si la república americana se hubiera encontrado frente a « cien reyes empeñados en perderla », también hubiera sucumbido. Castelar señala a Francia como " órgano o instrumento del progreso universal », origen de los derechos políticos y del sufragio universal con su "lógica inflexible $»^{30}$. Sin embargo, no existe el « progreso rectilíneo » y aunque una revolución vaya seguida « de una suspensión » o de un « retroceso », son quiebros necesarios "para la solución final que entrañan todas las revoluciones $»^{31}$. En realidad, unos años antes del citado prólogo equiparaba el fracaso de la Revolución francesa al del propio Cristianismo, que en su versión católica no logró pasar de la "esfera divina», como tampoco "pasó de la conciencia a la política » o de "los códigos civiles a los políticos» la Revolución francesa ${ }^{32}$. Fernando Garrido supera esas involuciones agrandando el horizonte revolucionario, pues para él no existen episodios revolucionarios sino una única revolución que "comenzó teórica», devino "política y y finalmente, en 1848, se convirtió en social ${ }^{33}$.

En la construcción de un imaginario revolucionario los actores deberían tener especial importancia, sin embargo, en los textos analizados, la Revolución francesa es exaltada como un gran relato histórico sin trama ni personajes. No se establecen paralelismos concretos, ni siquiera en los momentos de máxima tensión en el seno del republicanismo, como el levantamiento de octubre de 1869 o la insurrección cantonal. Aunque en muchos escritos se distingue entre el hombre de acción y el individuo consciente de su papel como referente intelectual del cambio, no aparecen comparaciones con los revolucionarios franceses. En algunos momentos ambas esferas se solapan, pero en otros las dos imágenes se oponen. Evidentemente, las propuestas más radicales y los intentos por ejecutarlas desde el federalismo merecen la crítica de los republicanos más comprometidos en la construcción de un discurso legitimador fundamentado en la continuidad. Manuel de la Revilla, que en sus primeros contactos con el republicanismo se manifestaba próximo a las posiciones jacobinas y federalistas, evoluciona durante el Sexenio hacia el entendimiento entre las diferentes posiciones republicanas, siendo muy crítico con los revolucionarios extremistas, caracterizados por la « intransigencia » que para él es una cualidad distintiva de « los jefes de segunda fila y los hombres de acción $»^{34}$. En la misma línea, Güell i Mercader señala que Roque Barcia encarna precisamente esa cualidad. Tras el fallido alzamiento cantonal de julio de 1873, Barcia reconoce el daño causado a la República por «las doctrinas intransigentes » que el mismo ha impulsado. Para el periodista catalán se trata de un acto de "contrición del famoso apóstol del cantonalismo", representante de la «revolución demagógica», que pone de relieve la necesidad de contar con «el elemento republicano histórico " sin el que la República es imposible »" Pero quizá uno de los individuos que mejor se ajusta a la imagen del revolucionario de acción es Froilán Carvajal y Rueda. Como en los casos anteriores se trata de una figura llena de contradicciones, empezando por un radicalismo político que no se corresponde con un discurso secularizador contundente. La publicación en su juventud de «El faro de la niñez", un compendio de "máximas religiosas, morales y sociales» dedicado a su amigo el presbítero D. Juan de Gavaldón Leal, no se ajusta al estereotipo del revolucionario anticlerical virulento. Concepción Cordero-Fernández le describe como " un hombre de acción ", « dotado de una enorme carga sentimental y de idealismo que 
se acababa imponiendo siempre a su capacidad de raciocinio ». En el periódico que dirigió, La Revolución (27 agosto de 1869), se le describe como « incansable obrero de la regeneración social de nuestra patria ». Sus escritos y acciones le sitúan en el marco del romanticismo. Representa « un epígono del arquetípico bandido generoso (que robaba al rico para socorrer al pobre) que pasó a convertirse en tópico de nuestra Guerra de Liberación (1808-1814)». El episodio del reto a duelo lanzado a Prim y al gobernador civil de Alicante, González Llana, en un artículo publicado en el mismo periódico (18 de agosto de 1869) titulado "Albricias", constata ese halo romántico que le acompañó hasta su ejecución, ante la que demostró la « serenidad de un caballero cristiano » ${ }^{36}$.

\section{La secularización como coeficiente de movimiento revolucionario y elemento legitimador}

Koselleck vincula la revolución a la existencia de unos coeficientes de movimiento destinados a legitimarla. Parte de la idea de «revolución absoluta », acuñada por el filósofo y jurista conservador Friedrich Julius Stahl en 1848 para quien todo movimiento revolucionario aspira a legitimar su razón de ser y su continuidad a través de una imagen dinámica dirigida a movilizar « la historia desde los correspondientes proyectos de futuro ». En el proceso resulta imprescindible fijar la imagen de un adversario permanente que justifique precisamente dicha continuidad ${ }^{37}$. Es en este punto en el que entra en juego la secularización como uno de los coeficientes de movimiento más efectivos a la hora de proyectar socialmente el dinamismo revolucionario, que en el caso que nos ocupa, se centra en una lucha sin tregua contra las fuerzas de la reacción, encabezadas por una Iglesia intransigente ${ }^{38}$. Más allá de los planteamientos racionalistas en torno a la necesidad de desligar la religión de la esfera pública que subyacen en la propia definición del concepto, las diversas manifestaciones secularizadoras permiten preservar la inercia revolucionaria sin adentrarse en la cuestión social, lo cual encaja perfectamente con las aspiraciones de una parte importante del republicanismo septembrino. Así, en los discursos de la época se suma a la tradicional retórica anticlerical, la voluntad de visibilizar el éxito de la revolución y su conexión con un ideal de progreso irreversible. En el alambicado discurso revolucionario las alusiones a la secularización como fuerza motriz o mera expresión transgresora siguen una cadencia ligada al propio devenir político que no puede ser ignorada. Buena prueba de ello nos la ofrece la citada Declaración de la Prensa, un texto político para consumo interno de los republicanos, publicada el 7 de mayo de 1870 y suscrita por los representantes de los periódicos republicanos madrileños La Discusión, El Pueblo, Gil Blas, La Igualdad, La República Ibérica y El Sufragio Universal. La Declaración se opone al federalismo pactista y al radicalismo en un discurso muy ecléctico. Podemos considerarla un punto de inflexión en el republicanismo revolucionario que abrió una gran fisura tras la insurrección federal del otoño del 69. Evidentemente para los federales el texto mostraba «la República mentira que desean los mal llamados republicanos que nos han insultado por medio de su periódico único, llamándonos bandoleros ${ }^{39}$. Pero lo que realmente llama la atención desde nuestra perspectiva de análisis, es que las propuestas secularizadoras brillan por su ausencia. Las referencias a la libertad son constantes, pero salvo alguna alusión al pontificado infalible de Pio IX, no se presta atención a la libertad de cultos o a la separación Iglesia-Estado, que en cambio sí llena la prensa republicana y las proclamas de las juntas. Precisamente 
muchas de ellas encabezan sus llamamientos con medidas tan contundentes como la expulsión de los jesuitas, disminución en el número de monasterios y rebaja en las dotaciones al clero, supresión del clero colegial, reducción de las diócesis, libertad de exclaustración $\mathrm{n}^{40}$, o como en la junta de Reus, la declaración del domingo como día laborable y por supuesto, la secularización de los cementerios y el matrimonio civil ${ }^{41}$. En este sentido, merece especial atención la guía para la celebración del matrimonio civil en Reus, escrita por el escritor y periodista republicano Güell y Mercader ${ }^{42}$. Ya en la primeras líneas expresa la utilidad de "esta gran conquista de la revolución moderna " para " que sea fecunda en resultados la revolución de setiembre », perviva su fuerza original y el «verdadero numen revolucionario $»^{43}$, frente a la ralentización que preconizaban « los hombres de Madrid». Por su parte, la junta revolucionaria de la ciudad de Reus había expresado ya su resistencia a la disolución «mientras hubiese en España una población de alguna importancia que la acompañase en su patriótica resolución ». Según Pere Anguera, los acontecimientos vividos en Reus y la apuesta por implantar el matrimonio civil constituyen una muestra de cómo la utilización de los elementos indiscutiblemente más progresistas tenía un único objetivo: afianzar la revolución en la ciudad ${ }^{44}$.

Aunque en muchas ocasiones la secularización forma parte de una retórica destinada a avivar la llama revolucionaria, también contamos con muchos ejemplos en los que se razona su legitimidad. Las alusiones al derecho natural constituyen una muestra clara en este sentido porque apelan a un orden derivado de la revolución que se "pre-vé ». Desde esta perspectiva el deber ser inherente al discurso revolucionario no es ideal o abstracto sino que se halla implícitamente contenido como posibilidad de cambio histórico a partir de unas libertades « formalmente presentidas ». En esta construcción discursiva las medidas secularizadoras se presentan a la vez como objetivo y resultado de un proceso imparable que no deriva tanto de la sanción legal como de una lógica natural. Güell y Mercader arguye razones que «se producen instintivamente en la conciencia », en una sociedad asentada "sobre bases distintas» en la que «la moral universal (y) el sentimiento instintivo del bien regula, más que las leyes, nuestras acciones" y se impone en la "conciencia de la opinión", de tal forma que el matrimonio civil puede decirse que « es ya una ley en España ». Desde esta posición la ley no es el punto de partida sino el de llegada; no ratifica una voluntad abstracta sino derivada de la historia que la lógica interna de la revolución materializa porque el «matrimonio como la familia ha nacido de la sociedad, ha existido mucho antes del establecimiento de todas las religiones positivas, ha existido completamente separado de la religión en todos los pueblos del mundo durante la edad antigua de la historia ; existe así mismo como una institución civil, desde la gloriosa revolución francesa de 1789 en todos los países donde la teocracia no domina». Güell admite que su aprobación puede suscitar en el «vulgo» cierta «repugnancia» o el «temor a la inestabilidad». Sin embargo, las probables críticas suelen proceder de los eslabones sociales más próximos a la reacción entre los que se encuentra la "mujer ", que evidentemente "desempeña un papel importante" en este asunto. El republicano espiritista Ramón Lagier también alude a este punto en sus memorias. Su voluntad de celebrar la unión civil no pudo superar las reticencias de su mujer y la familia, aunque con el tiempo, y tras recibir instrucción « ella se arrepintió » de « haber llamado a las puertas de la Iglesia para unirnos $»^{46}$. 
16 Si continuamos con el análisis del opúsculo encontramos perfectamente acotados los planteamientos teóricos apuntados anteriormente. Güell se refiere a la libertad de cultos y al matrimonio civil inherente a su aprobación, como una libertad « ilegislable», puesto que se encuentra en la esfera del derecho natural del hombre, cuyas creencias solo obedecen a los dictados de la conciencia. En el texto subyace la idea de una libertad latente, casi ajena a la voluntad humana pues « contra los derechos naturales no tienen autoridad ni las Cortes constituyentes ni la tiene nadie». En el mismo sentido se manifiesta el citado Lagier en una composición literaria anterior a la Gloriosa en la que dialoga con la mismísima libertad que « dejaría de serlo » si se llegara a codificar. El resultado siempre es el mismo: un «reglamento más que habrá que añadir a tantos reglamentos inútiles, un pacto escrito, una letra muerta ¿Quién es el hombre para dar limosnas de libertad ? $»^{47}$.

17 Las referencias a la Revolución francesa « del pasado siglo » constituyen igualmente la evidencia de una legitimidad subyacente, porque la Iglesia se arrogó en el pasado una atribución «que no debió tener nunca». Cualquier traba a la aprobación del matrimonio civil supone una "mengua » para «la revolución española de septiembre que está destinada a despertar a Europa a la vida del derecho» y por tanto debe establecerlo "sobre bases sólidas e indestructibles». La revolución se presenta así imbricada en una tradición nacional configurada desde tiempo inmemorial ${ }^{48}$.

Güell menciona a Portalis en su opúsculo. El principal impulsor del código civil francés, que podemos situar en las antípodas del radicalismo revolucionario, señala que el derecho natural es el fundamento del derecho positivo: "A falta de ley hay que recurrir a la costumbre y la equidad. La equidad es el retorno a la ley natural, ante el silencio, la contradicción o la oscuridad de las leyes positivas ». El jurista francés se muestra partidario de no aislar las « instituciones de cuanto puede naturalizarlas sobre la tierra » y de « observar con cuidado las relaciones naturales que siempre ligan más o menos el presente con el pasado y el porvenir con el presente ${ }^{49}$. Estas máximas fundamentan el rechazo a la improvisación en los argumentos favorables al matrimonio civil. Güell advierte en su guía que « el legislador no puede preverlo todo por sí, debe de confiar a la sabiduría de los otros lo que de antemano no podría arreglar con acierto ». Incluso cuando valora la posibilidad del incesto y el tema de las dispensas matrimoniales en un periodo de transición hacia la aprobación definitiva de la ley, el republicano reusense apela a las "leyes físicas de la naturaleza », compartidas por «todos los pueblos independientemente de toda comunicación que pudiesen haber tenido $»^{50}$.

19 Los argumentos de Fernando Garrido respecto a la legitimidad natural del avance secularizador son más simples. Al igual que Güell, Garrido lo identifica ligado al progreso cuyos obstáculos son interpretados en clave anticlerical, de forma que su visión de la revolución pasa por la lucha contra « este formidable enemigo, que devora las entrañas de la sociedad». Como señalábamos en el epígrafe anterior, la imagen de una victoria sobre el adversario clerical es la condición para que pueda consolidarse "nuestra revolución ${ }^{51}$. El resultado de ese combate es la mengua gradual del pensamiento teocrático o como en ocasiones señala « del poder negro ». En su obra Historia de las clases trabajadoras presenta en una tabla la imagen del retroceso. Desde 1797 la población española empieza a crecer por el «influjo de la filosofía racionalista »; en 1820 el crecimiento se mantiene "por las revoluciones políticas anticatólicas »; en 1835 la «desamortización eclesiástica » y «la expulsión del clero del 
poder político " son factores positivos para el desarrollo hasta llegar a 1870, con «la caída de los Borbones, de los últimos restos de las influencias teocráticas del poder » y el « advenimiento de las doctrinas democráticas y la libertad de cultos ${ }^{52}$.

Junto al derecho natural, la otra gran línea que fundamenta la continuidad en los discursos republicanos es el cristianismo. En este punto nos interesa analizar aquellos discursos que plantean la idea de una continuidad cristiana «desviada» de su ruta original, falseada por la teocracia y el clericalismo. Como señala « el incansable propagandista republicano $»^{53}$ Roque Barcia, « el genio papal » no es más que « una contradicción casi continua del genio cristiano $»^{54}$. Dejamos de lado el tradicional argumentario anticlerical o las posiciones próximas al ateísmo que defienden republicanos como Suñer y Capedevila ${ }^{55}$ o Pi y Margall, quien desde planteamientos hegelianos afirma que "la religión es un producto del pasado ». El que fuera segundo presidente de la República no reconoce en la religión ninguna continuidad. Aunque la reconoce como "punto de partida para la razón » ha sido superada por la ciencia porque no ha aportado nada al « terreno de la alta abstracción y la teoría » ${ }^{56}$.

Frente a las posiciones materialistas, la concepción Krausista de la religión la posiciona " como elemento esencial a la vida del hombre" pero en un sentido moderno que reconoce « una secularización de las instituciones que no de la sociedad ${ }^{57}$. Desde esta línea de pensamiento y en las mismas coordenadas derivadas del derecho natural, Emilio Castelar nos habla de una misión civilizadora originada en el cristianismo que evoluciona en el tiempo hacia una « obra social », a través de un proceso revolucionario abierto que culminará con la " Democracia ». De esta forma se unen « los dos polos de la historia, el Cristianismo y la revolución, el siglo I y el siglo XIX $»^{58}$. En La fórmula del Progreso, señala que la democracia no es contraria al cristianismo, como dicen sus enemigos, sino que es « la realización social del Cristianismo " ${ }^{59}$.

Ya en pleno Sexenio, en su discurso parlamentario en defensa de la libertad religiosa, reitera esta idea centrándola en la propia religión, que como en el caso del derecho natural, nunca puede ser impuesta a través de la legislación sino «aceptada por la razón y la conciencia». En España «lo antiguo es la libertad, lo moderno el despotismo ». Por tanto existe un hilo conductor para las libertades cuya trayectoria fue desviada a partir del siglo xIv, con la Contrarreforma y la injerencia del jesuitismo ${ }^{60}$. Ocho años después, ya pasada la experiencia revolucionaria y republicana, Castelar incide en estas mismas ideas al señalar que si en « los tiempos antiguos » se creía " que la religión era obra del Estado" en "nuestro tiempo la religión es obra de la conciencia » y por tanto no hay « ley civil » o « ley política » que puedan construir una realidad ajena al devenir natural ${ }^{61}$. Desde esta perspectiva la legitimidad de las propuestas secularizadoras no pueden proceder de la ley positiva porque la separación entre una esfera religiosa y otra civil es inherente al propio cristianismo. Todo el desarrollo posterior, ligado a la Iglesia y al clero, es ajeno a su verdadera naturaleza.

El también republicano Mariano Calavia, considera que la revolución es una « explosión sublime y llena de un ideal glorioso » con una función correctora sobre una continuidad truncada, al barrer la « basura hasta entonces desparramada por el suelo español por la tradición y por la historia $»^{62}$. En un texto de 1868 plantea la idea de una esencia nacional como " eternidad inquebrantable ", « roca granítica resistente a las invasiones y a las influencias extrañas » y alude al " genio del país » frente al absorbente « espíritu católico", culpable de que la patria haya perdido la «iniciativa individual que se ha atribuido como peculiar a la raza germánica ». Los acontecimientos históricos han 
desviado «la indomable fiereza española" que a pesar de todo se « ha conservado latente ». Calavia considera que ha habido "una equivocación secular» que "nos traído a la confusión de la unidad nacional refundida en la unidad católica, que como bandera enarbolamos en la reconquista ». El catolicismo, que fue útil para que los Reyes católicos organizaran la unidad patria, se injirió posteriormente en el poder propiciando "nuestra decadencia, nuestro aislamiento, nuestra tisis " ${ }^{63}$. En la misma línea, aunque más abierto a la idea de perfectibilidad, se expresa Garrido que en un discurso en las Cortes Constituyentes señala que «necesitamos consultar la historia, que es la gran maestra de la humanidad » para salir del atraso. De ella aprendemos que « la revolución desde fines de la Edad Media en España y en las demás naciones ha sido un ataque constante a la teocracia romana, de modo que la decadencia del catolicismo, representado por la curia romana, ha sido proporcionada al progreso de la libertad, de la civilización y de las ciencias $»^{64}$.

Entre las referencias a una continuidad revolucionaria y secularizadora, dentro de los cauces cristianos, abundan los textos que presentan a Cristo como un revolucionario o el primer republicano, aunque en ocasiones el interés por encontrar un hilo legitimador puede remontarse al propio Sócrates que en realidad « fue el primer mártir de la verdad ", seguido por Jesucristo que predicó « la emancipación del hombre » y el "verdadero espíritu de justicia » principios fundamentales que integra " una doctrina que tuvo por cátedra la cruz $»^{65}$ y que como señala una publicación espiritista del momento, se convierte a través de la república en el « madero regenerador ${ }^{66}$.

De la oposición entre "los sistemas religiosos y políticos disecados en dogmas y sostenidos en la autoridad y el despotismo " y la revolución emerge una primigenia libertad que representa la "religión de la interioridad y de la libertad». El impulso secularizador derivado de ese choque no se proyecta como un nuevo orden sin fundamentos sino como una fuerza restauradora. Desde esta perspectiva la religión es reinterpretada sobre la base de la conciencia individual, en un proceso que corre paralelo al rejuvenecimiento de un orden político y moral degradado y decadente. El objetivo es restituir la perfección originaria y restablecer la edad de oro de un mítico pasado a partir de una lectura milenarista y optimista de la Revolución francesa como punto de arranque ${ }^{67}$. En este sentido se expresa el periodista republicano Bernardo García en una carta escrita a Ramón Lagier sobre el imaginario cristiano y la idea de continuidad: «Doce apóstoles convirtieron el mundo al cristianismo ¿por qué cientos de ellos no han de convertir la España en Republicana? ». Aunque la reacción presenta al « espíritu revolucionario » como una ruptura traumática que promueve « los malos instintos de las masas ", su misión verdadera es abrirles los « ojos a la contemplación del hermoso porvenir que les espera con la República ${ }^{68}$. Al fin y al cabo «la República procede de Dios " y por tanto "Dios fue el primer republicano ", cuyo hijo fue el primer mártir que "murió por la libertad de pueblo $»^{69}$. El propio Lagier considera que esa misión procede de una « ley divina $»^{70}$.

Por último nos queda por identificar la idea de evolución y de continuidad revolucionaria y secularizadora a través de la comparación con otros países. Una vez más, Fernando Garrido, en su discurso ante las Constituyentes, construye un relato de progreso para legitimar la revolución como proceso universal. Señala que «las naciones que nos han precedido en el camino de la libertad», son aquellas que nos llevan tres o cuatro siglos en la ventaja de haberse librado de la solitaria romana (...) : la Inglaterra, Holanda, la Alemania y Suiza, esas naciones han tenido, no solamente más 
libertad política, sino que también han realizado grandes progresos en las ciencias, en las artes, en todos los conocimientos humanos, hasta hacer preciso confesar que no son los pueblos católicos, sino los anti-católicos, los que marchan a la cabeza de la civilización moderna ${ }^{71}$. En esta misma línea las referencias en la prensa son constantes. En 1869 un periódico local señala que «nuestro deber es ponernos a la altura de lo que hoy se piensa, ya que tenemos ahora ocasión de hacerlo $»^{72}$. Güell y Mercader en su guía para implantar el matrimonio civil en España alude a « la gloriosa revolución francesa » que lo sancionó por primera vez en « todos los países en donde la teocracia no domina » y "existirá mañana en todos los pueblos civilizados, cuando el poder social se emancipe completamente de la tutela religiosa ». Al igual que Garrido cuando alude a una clase trabajadora en Inglaterra "completamente secularista", enemiga de «todas las religiones $»^{73}$, Güell asume que la « completa secularización de todas las instituciones sociales » es un hecho constatado en todos los países avanzados, manifiesta en el "espíritu público», fruto del sentido común e inherente a la modernidad que ha hecho perder relevancia « en la inteligencia a la idea religiosa $»^{74} . \mathrm{Si}$ avanzamos un poco en el tiempo y recuperamos nuevamente la figura de Güell y Mercader en su faceta de redactor para periódicos latinoamericanos, observamos que reaparece la idea de continuidad truncada. Ya desde los últimos momentos de la República, el escritor catalán asume el fracaso de la revolución y el consiguiente triunfo de la reacción. Sus cartas a los periódicos americanos nos hablan de un país que ha perdido el tren de la modernidad en comparación con otras naciones. Si la revolución había visibilizado el hilo conductor que transmitía la corriente del progreso y la libertad, su final constataba la existencia de un reverso para la involución y el retroceso; un hilo igualmente poderoso que permitía identificar en España una reacción con carácter propio, especialmente virulenta si se compara con los procesos reaccionarios de otros países. En realidad, toda revolución conlleva una reacción. Es la idea que defiende Castelar, en su prólogo a la obra de Thiers sobre la Revolución francesa. Señala el último presidente de la República que no conoce « revolución alguna la cual no haya sido acompañada de aquello que la constituye esencialmente, de una suspensión, de un retroceso, de una serie de retrogradaciones llamadas en la lengua política reacción ». Son " descansos » necesarios "para la solución final que entrañan todas las revoluciones $»^{75}$. Sin embargo, aunque Güell pueda aceptar este esquema dialéctico, opina que existen avances con un carácter inmutable e irreversible, como demuestra la Francia postrevolucionaria. Incluso «tras la restauración borbónica de 1815 fue prudente para conservar la libertad de cultos y la igualdad de todos ante la ley, el registro y matrimonio civil, el jurado y algunas reformas revolucionarias de carácter y transcendencia social $¡ Y$ eran realistas puros los que así obraban el día del triunfo honradamente obtenido!». En cambio, la naturaleza de la reacción en España, con sus involuciones absolutas, justificaría la violencia de nuestras revoluciones ${ }^{76}$.

27 En un contexto complejo y de indecisión política, tras el episodio de la Comuna y la humillación ante Prusia, la Asamblea Nacional francesa fue testigo de la última batalla entre la opción monárquica y la republicana, en un proceso que se prolongaría hasta 1879 con la renuncia de Mac-Mahon. Estos años marcaron las crónicas de Güell que presentan la imagen de un pueblo francés en ocasiones de "espíritu superficial y novelero » pero cuya "genealogía y audacia reformista», consolidan su proyección internacional como "pueblo revolucionario por excelencia ». Pero las comparaciones no se reducen a Francia. En Inglaterra no hay revoluciones « desde que los reyes de la casa de Orange no resisten al Parlamento », « ¡Dichosa Inglaterra, en donde el progreso 
político no sufre con los cambios de gobierno!». En Italia «tienen un partido conservador decente $»^{77}$, y en Alemania, en pleno enfrentamiento entre Bismarck y el papado, pervive la educación cívica frente a la educación religiosa que solo produce «buenos vasallos $»^{78}$. Ya con Alfonso XII en el trono, Güell destaca la intervención de Inglaterra y Alemania para que no se decrete la intolerancia religiosa "porque apartaría a España del concierto de pueblos civilizados $»^{79}$.

En sus crónicas, España y Francia están unidas «por la expectación mundial » para dirimir « el gran problema del viejo mundo en su lucha titánica » contra la monarquía y la tradición ${ }^{80}$, aunque los españoles están perdiendo la partida. El rebrote del clericalismo en los años setenta parece constituir una tónica general en Europa. Tras los acontecimientos de 1871, la paz en Francia « ha dado vida al insecto clerical » $\mathrm{y}$ « sin embargo la Francia no es clerical» como tampoco lo es España. La protección del clericalismo es evidente en suelo francés, visible en la revitalización de las "procesiones, pastorales y proclamas que cubren las puertas de las iglesias». Un rebrote que deja asombrada a la «Europa liberal » que contempla la involución de una nación « tenida hasta hace poco como « el cerebro de las ideas modernas y convertida hoy como por arte de encantamiento en nación clerical ». En Madrid se observa un proceso similar impulsado por «nuestros monárquicos que se entregan a la apacible ocupación de las ceremonias cortesanas resucitando con motivo de la semana santa todas las costumbres ", excitando " por todos los medios posibles el fanatismo religioso, causa de nuestras desgracias » y que la revolución « había logrado arrinconar ». Sin embargo, en condiciones similares, en el país vecino se vislumbra un rayo de esperanza con la renovación de la Asamblea, que permitirá que prevalezca « el verdadero espíritu de la Francia moderna", mientras que aquí nos encontramos con el «espectáculo de una España empeñada en destruirse a si propia y acabar con todo lo que puede sostener en ella su poderosa nativa virtualidad $»^{81}$. Güell describe el proceso como un quiebro en el camino de una revolución que curiosamente se inició con un gran impulso secularizador y cuyo final queda sellado precisamente con medidas que representan una " humillación a los pies de Roma »: el " arreglo del clero », que deja vía libre para el control de la Iglesia sobre la educación, la modificación del matrimonio civil, con "gran escándalo de los hombres de ley» al otorgar nuevamente valor legal al matrimonio religioso. Medidas que « dan al mundo civilizado una imagen de nuestras detestables costumbres políticas ». El periodista catalán defiende la obra revolucionaria como un impulso homogéneo dirigido a ejecutar grandes reformas que desde su perspectiva no son fruto de la espontaneidad o el oportunismo político sino que derivan de " años de preparación infinita » atribuidos a " toda una generación de reformistas ", que actuaron con " prudencia y circunspección ${ }^{82}$.

Pero las referencias internacionales no se circunscriben a Europa. América es también un punto de referencia obligado. Garrido, al igual que Güell, concede gran importancia a la educación y la instrucción de la juventud. Por ello Estados Unidos es una república federal modélica porque el Estado no sostiene a « las religiones y sus cultos $»^{83}$. Para el republicano catalán América es el « continente de la libertad y la democracia », con el que nos une una « cariñosa fraternidad ». Es el foro al que se dirige Güell para defender "seis años de laboriosa gestación » cuyos frutos han sido objeto de "aplauso de todos los pueblos libres e ilustrados ${ }^{84}$. Ante la celebración de una exposición universal en 1876 en Filadelfia, el "corresponsal en España ", se refiere a la raza íbera y al tercer lugar que ocupó España entre las naciones premiadas. Un claro signo de progreso pero también de cómo un gobierno puede llegar a ser una rémora para el desarrollo si no 
trabaja «por el bien general» y no representa al verdadero genio nacional. Las alusiones a una república universal se convierten en un grito de auxilio para un país que ha visto truncado un desarrollo impulsado por la revolución y legitimado por una república traicionada ${ }^{85}$.

\section{Conclusiones}

Como en otros procesos revolucionarios de carácter burgués, la Gloriosa abrió una línea de tensión entre un horizonte de expectativa y el desnivel de experiencia que pretendía dejar atrás, representado por la monarquía y la Iglesia. El relato(s) revolucionario se mueve así en un equilibrio inestable en el que cuanto menor es el contenido de experiencia referida, mayor será la expectativa proyectada, en una retórica de progreso irreversible que corre el peligro de ser percibido como una mera anticipación sin ningún fundamento político, social o económico. La idea de ruptura respecto a un pasado vencido resulta útil para amalgamar voluntades en los primeros momentos revolucionarios. Sin embargo, la eficacia del discurso insurgente depende de que pueda evolucionar hacia un imaginario transformador, en el que las referencias a la experiencia adquieran mayor peso. A pesar de las divergencias en torno a los elementos que deberían conformar un relato fundacional sobre el que no existe consenso, desde el republicanismo histórico se aprecia cierta unicidad sobre la necesaria construcción de una nueva legitimidad que sin renunciar a la idea de cambio lograra despegarse gradualmente del componente subversivo. El reto es estabilizar un nuevo relato identitario que integre la porción justa entre la idea de ruptura y de continuidad ; una labor especialmente ardúa para una opción política cuyo discurso nuclear se fundamenta en la subversión del orden establecido.

\section{NOTAS}

1. Micheline milot, La Laïcité dans le nouveau monde, le cas du Québec, Turnhout, Brepols, 2002, citado por Jean BAUBÉROT, «Identidad nacional en la laicidad francesa », en Roberto J. BLANCARTE (coord.), Los retos de la laicidad y la secularización en el mundo contemporáneo, México, Colegio de México, 2008, p. 56.

2. Rafael SERRANO GARCíA, « La biblioteca de un texto vivo (en torno a los orígenes intelectuales de la Revolución », Ayer, nํ112, 2018 (4), p. 29.

3. Marcelino MENÉNDEZ PELAYo, Historia de los heterodoxos españoles, Madrid, Librería Católica de San José, 1881, t. III, p. 809.

4. Alicia MIRA ABAD, Secularización y Mentalidades. El Sexenio Democrático en Alicante (1868-1875), Alicante, Publicaciones de la Universidad de Alicante, 2006, p. 47-55; Reinhart KOSELLECK, En futuro pasado. Para una semántica de los tiempos históricos, Barcelona, Paidos, 1993, p. 328-357.

5. Marie-Angèle OROBON, « La carne de la política : ruptura democrática y simbología », Ayer, nº $112,2018(4)$, p. 75. 
6. Gonzalo CAPELLÁN DE MIGUEL, « ¿Mejora la humanidad? El concepto de progreso en la España liberal », en Manuel SUÁREZ CORTINA (ed.), La redención del pueblo. La cultura progresista en la España liberal, Santander, Universidad de Cantabria, 2006, p. 55-6.

7. Gerhardt LADNER y Marjorie REEVES son citados por Robert NISBET, Historia de la idea de progreso, Barcelona, Gedisa, 1996, p. 80-81.

8. Hannah ARENDT, Sobre la revolución, Madrid, Alianza Editorial, 1988, p. 26-27.

9. Enrique PRUGENT LOBERA, El 29 de septiembre de 1868 o la Apoteosis de la libertad, Zaragoza, Tipografía de Ballés y Malo, p. 1-15

10. « El Comité Republicano de Madrid. A los electores », La Igualdad, 18-XI-1868.

11. Enrique PRUGENT LOBERA, El 29 de septiembre de 1868..., p. 11

12. Caracterizaciones realizadas por GÜELL Y MERCADER en sus escritos para periódicos latinoamericanos : La Tribuna 25-X-1873 y El Monitor Republicano de México, 29-III-1874 (Archivo Histórico de Reus)

13. Florencia PEYRou, « Ciudadanía, República, Libertad. Las voces de la Democracia, 1840-1890 », en Manuel PÉREZ LEDESMA, (ed.), Lenguajes de modernidad en la Península Ibérica, Madrid, UAM, 2012, p. 169.

14. Julián SAUQUILLO, « Revolución y secularización », Isegoría, nำ39, 2008, p. 16-17.

15. Manuel DE LA REVILLA, Historia y Defensa de la Declaración de la prensa republicana, Madrid, Imp. de La Discusión, 1870, p. 7-8.

16. Discurso del diputado por Sevilla Luís del Río. DSCC, Sesión del 8 de marzo, legisl.1869.

17. La Tertulia, 21-I-1873.

18. Juan PRO RUIZ, « Mujeres en un estado ideal : la utopía romántica del fourierismo y la historia de las emociones" Rubrica contemporánea, vol. 4, nº 7, 2015. Vid. Ricardo NAVAS RUIZ, El romanticismo español, Madrid, Cátedra, 1990. Paloma CIRUJANO MARÍN, Teresa ELORRIAGA PLANES, Juan SISINIO PÉREZ GARZÓN, Historiografía y Nacionalismo español. 1834-1868, Madrid, CSIC, 1985, p. 13-87 y 187-188.

19. Manuel DE LA REVILLA, « La Filosofía española. Contestación a un artículo del señor Menéndez y Pelayo », Revista Contemporánea, 15-VIII-1876, 17, T.V, vol. I, p. 111-115

20. Alain TOURAINE, Crítica de la modernidad, Madrid, Temas de hoy, 1993, p. 178-183.

21. Antonio GRAMSCI, Cuadernos de la cárcel. Edición crítica del Instituto Gramsci a cargo de Valentino Gerratana. T.I. Cuaderno I, nota 150. México, Ediciones Era, 1981, p. 189.

22. Philippe BÉNÉTON, Historie de mots: culture et civilisation, Paris, Presses de la Fondation Nationale des Sciences politiques, 1975, p. 12-68.

23. Manuel DE LA REVILLA, Historia y Defensa de la Declaración... p. 16, 39 y 46.

24. Emilio CASTELAR, "Manifestación republicana", La Igualdad, Madrid, Suplemento Extraordinario, 30-XI-1868.

25. Dalmacio NEGRo PAVÓN, Anuario Filosófico, 1983 (16), p. 81-105.

26. Antonio MOLINER PRADA, Revolución burguesa y movimiento juntero en España, Lleida, Milenio, 1997, p. 351.

27. Manuel DE LA REVILLA, Historia y Defensa de la Declaración...., p. 16.

28. Reinhart KOSELLECK : Futuro pasado...., p. 67-85.

29. Juan FRANCISCO FUENTES y Javier FERNÁNDEZ SEBASTIÁN, "The concept of Revolution in nineteenth-century Spain », The European Legacy, vol. 5, 3, 2000, p. 358.

30. Emilio CASTELAR, Historia de la revolución francesa. Un prólogo a Thiers (Prólogo de Francisco Villacorta Baños), Pamplona, Urgoiti, 2009, p. 279-80.

31. Ibid., p. 11.

32. Emilio CASTELAR, La fórmula del progreso, Madrid, Tip. J. Casas y Díaz, 1858, p. 67. 
33. Fernando GARRIDO, Historia de las clases trabajadoras, de sus progresos y transformaciones económicas, sociales y políticas, desde los tiempos más remotos hasta nuestros días, con las biografías de sus grandes hombres, de sus héroes y mártires más famosos, escrita y dedicada a todos los amantes del progreso, Madrid, Imp. T. Núñez Amor, 1870, p. 857.

34. Manuel DE LA REVILLA, Declaración de la prensa ..., p. 15.

35. Josep GÜELL Y MERCADER, El Monitor republicano (México), 29-I y 26-II-1874.

36. Concepción FERNÁNDEZ-CORDERO AZORÍN, «El republicanismo federal en Alicante: Froilán Carvajal y el diario La Revolución », Anales de Historia Contemporánea, n 3, 1984, p. 69-99. El faro de la niñez. Colección de máximas religiosas, morales y sociales, Madrid, Imprenta de Manuel Minuesa, 1864.

37. Reinhart KOSELLECK, En futuro pasado..., p. 83.

38. Vid. Daniele mENOzZI, La chiesa cattolica e la secolarizzazione, Torino, Einaudi, 1993.

39. El « Manifiesto » en La Revolución, 14-III-1870.

40. Pedro Antonio PERLADO, La libertad religiosa en las Constituyentes del 69, Pamplona, EUNSA, 1970, p. 58-60.

41. Valeriano BozAL, Juntas Revolucionarias. Manifiestos y proclamas de 1868, Madrid, Cuadernos para el diálogo, 1968, p. 45.

42. José GÜELL Y MERCADER, El matrimonio civil según se practica en la ciudad de Reus. Guía y formulario para la celebración de este acto tan importante, Reus, Imprenta de Francisco Vidiella, 1869, p. 9-12.

43. La Constitución francesa de 1791 en su artículo $7^{0}$ establece que «la ley considera el matrimonio como contrato civil, el poder legislativo establecerá para todos los habitantes, sin distinción, el modo por el cual los nacimientos, matrimonios y defunciones serán constatados y designará qué oficiales públicos recibirán las actas de ellos ».

44. Pere ANGUERA, La burgesia reformista. Reus en els fets de l'any 1868, Reus, 1980, p. 169 ; Roberto ROLDÁN VERDEJO señala en este sentido que era un asunto de « urgencia política » y compromiso de las juntas, impulsoras de la revolución. La ley de matrimonio civil. Una ley olvidada, Granada, Universidad de Granada, 1980, p. 108-109.

46. El Sentido, (Lérida) Octubre de 1883. La Revolución en 1870 alude igualmente a "las aprensiones » que infunde «en las personas timoratas la consagración de su matrimonio por medio de la ley civil ».

47. Pedro IBARRA, R. Lagier, Apuntes para ilustrar la biografía del bravo capitán del Buenaventura, Elche, Francisco Fernández Díaz, 1901, p. 107.

48. Paloma Cirujano marín, Teresa elorriaga planes, Juan Sisinio pérez garzón, Historiografía y Nacionalismo español..., p. 73.

49. «De Montesquieu a Portalis », Intervención de Juan VALLET DE GOITYSOLo en la Real Academia de Ciencias Morales y Políticas el 7 de noviembre de 1989, p. 7.

50. José GÜELL Y MERCADER, El matrimonio civil según se practica en la ciudad de Reus..., p. 9.

51. Fernando GARRIDO, « La revolución religiosa », La Discusión, Madrid, nº 3, 8-X-1868, p. I. Citado en Gregorio de la FUENTE MONGE y Rafael SERRANO GARCíA, La revolución Gloriosa. Un ensayo de regeneración nacional (1868-1874). Antología de textos, Madrid, Biblioteca Nueva, 2005, p. 131.

52. Fernando GARRIDO, Historia de las clases trabajadoras..., p. 218.

53. Los diputados pintados por sus hechos, Madrid, R. Labajos y Compañía, 1869, p. 447-449.

54. Roque BARCIA, Cuestión pontificia, Madrid, Establecimiento tipográfico de R. Vicente, 1855, p. 27.

55. Vid. Francisco, SUÑER Y CAPDEVILA, Dios, Madrid, Imp. de Domingo Blanco, 1869.

56. Francisco PI Y MARGALL, La reacción y la revolución, Barcelona, 1854, p. 17.

57. Manuel SUÁREZ CORTINA, Entre cirios y garrotes. Política y religión en la España contemporánea. 1808-1936, Santander, Universidad de Cantabria, 2014, p. 140.

58. Emilio CASTELAR, La civilización en los cinco primeros siglos del cristianismo, Madrid, Manuel Gómez Marín, 1858-1859, vol. III, p. 96 y vol. IV p. 67-80. 
59. Emilio CASTELAR, La fórmula del progreso, Madrid, Tip. J. Casas y Díaz, 1858, p. 54-55.

60. Emilio CASTELAR, « Rectificación al Señor Manterola sobre la libertad religiosa y la separación entre la Iglesia y el Estado, pronunciada el 12 de abril de 1869 », en Discursos Parlamentarios en la Asamblea Constituyente, Madrid, A. de San Martín y Agustín Jubera, 1877, t. I, p. 253-279.

61. Emilio CASTELAR, «Introducción » a J. MARTÍN DE OLÍAS, Influencia de la religión católica, apostólica y romana en la España Contemporánea. Estudios de Economía social, Madrid, Lib. de Fco. Góngora, 1876, p. 16.

62. Mariano CALAVIA, España y la Democracia. Consideraciones crítico-históricas sobre la revolución de septiembre, Madrid, Enrique de la Riva, 1879, p. 16-17.

63. Mariano CALAVIA, Reflexiones acerca de la Gloriosa revolución de setiembre de 1868, Madrid, Imp. de Manuel Tello, 1868, p. 20-26.

64. Discurso pronunciado por Fernando Garrido, el 30 de abril de 1869, en las Cortes Constituyentes. Los Diputados pintados por sus hechos. Colección de estudios biográficos sobre los elegidos por el sufragio universal de las constituyentes de 1869. Recopilado por distinguidos literatos y seguido de un exacto e imparcial resumen histórico de las causas y efectos de la revolución española hasta el día en que las Cortes decidan la definitiva forma de Gobierno que ha de regir en la Nación. Ilustrada con magníficos retratos en litografía, por el acreditado artista Santiago Llanta. Madrid, R. Labajos y Compañía Editores, 1869, t. I, p. 226-237.

65. El Comercio, (Alicante) 8-III-1869.

66. La Revelación, (Alicante), 28-II-1873.

67. José María GARCíA GÓMEZ-HERAS, Religión y modernidad. La crisis del individualismo religioso de Lutero a Nietzsche, Córdoba, Publicaciones del Monte de Piedad y Caja de Ahorros de Córdoba, 1986, p. 120 y 123, 148-149 ; Marina CAFFIERo, « Profezia, apocalisse e milenio nell' Italia rivoluzionaria », Cristianesimo nella storia, Bologna, Istituto per le scienze religiose, 1989, X/2, giugno, p. 426-27.

68. Carta fechada el 14 de noviembre de 1868, en Pedro IBARRA, R. Lagier, Apuntes para ilustrar la biografía..., p. 85.

69. La República Española, (Alicante) 24-IX-1870.

70. «El Norte político ». Panfleto de propaganda electoral escrito por Ramón LAGIER el 11 de enero de 1869. Archivo Municipal de Elche, Tesoro Histórico de Pedro Ibarra, 1800-1900.

71. Discurso pronunciado por Fernando Garrido, el 30 de abril de 1869, en las Cortes Constituyentes, en Los Diputados pintados por sus hechos..., p. 226-237.

72. El Eco de Alicante, 6-III-1869.

73. Fernando GARRIDO, Historia de las clases trabajadoras, de sus progresos y transformaciones económicas, sociales y políticas..., p. 837.

74. José GÜELL Y MERCADER, El matrimonio civil según se practica en la ciudad de Reus. Guía y formulario para la celebración de este acto tan importante, Imprenta de Francisco Vidiella, Reus, 1869, p. 7.

75. Emilio Castelar, Historia de la revolución francesa..., p. 11-13.

76. La Idea, 17-VII-1874, (Archivo Histórico de Reus).

77. La Idea, 17-VII-1874, (AHR).

78. El Monitor republicano, 13-IV-1874, (AHR).

79. La Crónica, 6-III y 3-IV-1875, (AHR).

80. La Tribuna, 25-X-1873, (AHR).

81. El Nacional, febrero de 1874 ; La crónica, 3-IV-1875, (AHR).

82. La Idea, 17-VII-1874, (AHR).

83. Fernando GARRIDO, Historia de las clases trabajadoras, de sus progresos..., p. 784.

84. La Patria 20-VI-1875, (AHR).

85. La Crónica, 29-XII-1874, (AHR). 


\section{RESÚMENES}

Este trabajo se centra en los conceptos de revolución y secularización como fuerzas universales ligadas al progreso y la modernidad. En el Sexenio Democrático no se plantean como una ruptura total, sino que forman parte de una coartada legitimadora fundamentada en la historia, el derecho natural y el cristianismo. Los discursos republicanos integran de esta forma elementos aparentemente tan incompatibles como revolución o libertad con la idea de un orden ligado al sentido común y la historia. La búsqueda de líneas de continuidad proyecta la revolución como el proceso que ha hecho emerger la esencia liberal del pueblo español. En la misma línea, la secularización no cuestiona la religión sino la posición de la Iglesia católica como fuente de poder imbricada en las instituciones y en el imaginario social. Representa una desviación respecto a un supuesto cristianismo primitivo que la revolución tiene la ocasión de restaurar.

Ce travail est centré sur les concepts de révolution et de sécularisation en tant que forces universelles liées au progrès et à la modernité. Ces idées ne sont pas envisagées comme une rupture radicale, mais comme faisant partie d'un alibi de légitimation fondé sur l'histoire, le droit naturel et le christianisme. Les discours républicains intègrent de cette manière des éléments apparemment aussi incompatibles que la révolution ou la liberté avec l'idée d'un ordre lié au sens commun et à l'histoire. La recherche de lignes de continuité projette la révolution comme le processus qui a fait émerger l'essence libérale du peuple espagnol. Dans la même ligne, la sécularisation ne questionne pas la religion, mais le positionnement de l'Église catholique en tant que source de pouvoir imbriquée dans les institutions et l'imaginaire social. Elle représente une déviation par rapport à un prétendu christianisme primitif que la révolution a l'occasion de rétablir.

This work focuses on the concepts of revolution and secularization as universal forces linked to progress and modernity. In the Democratic Sexenio these ideas do not suppose as a total rupture, but they are part of a legitimizing alibi based on history, natural law and Christianity. The republican discourses integrate in this way elements apparently as incompatible as revolution or freedom with the idea of an order linked to common sense and history. The search for lines of continuity projects the revolution as the process that has made emerge the liberal essence of the Spanish people. Equally, the secularization does not question religion but rather the position of the Catholic Church as a source of power imbricated in institutions and in the social imaginary. It represents a deviation from a supposed primitive Christianity that the revolution has the opportunity to restore.

\section{ÍNDICE}

Mots-clés: Révolution, Sécularisation, « Sexennat Démocratique », Christianisme primitif.

Keywords: Revolution, Secularization, Democratic Sexenio, Primitive Christianity.

Palabras claves: Revolución, Secularización, Sexenio Democrático, Cristianismo primitivo.

\section{AUTOR}

\section{ALICIA MIRA ABAD}

Universidad de Alicante 